\title{
FAMILIA Y SOCIEDAD EN UN CONCEJO MARÍTIMO DEL NOROESTE PENINSULAR: EL MUNICIPIO ASTURIANO DE CARREÑO EN 1753
}

\author{
Patricia SUÁREZ ÁLVAREZ
}

\author{
Recibido: $15 / 06 / 2012$ \\ Aceptado: 04/11/2013
}

RESUMEN: Durante el Antiguo Régimen, la geografía y climatología del Principado de Asturias hizo del mar su principal vía de comunicación. Junto con los grandes puertos de Gijón o Avilés coexistían otras poblaciones marítimas «menores» que compaginaban el aprovechamiento de los recursos que el mar les ofrecía con la agricultura. Este es el caso de la villa de Candás, capital del concejo de Carreño, que durante el siglo XVI destacó por ser un importante puerto de pesca ballenera, muy conocido en la Europa norteña. La industria de transformación de los productos piscícolas, que derivó en el siglo XIX en la creación de las fábricas conserveras, permitió al concejo cierta supervivencia autónoma respecto a las grandes entidades evitando la retracción demográfica y económica. Para aproximarnos a su historia, mostraremos «una fotografía» de un año concreto del siglo XVIII, 1752-53, y analizaremos la tipología familiar y profesional del concejo y su relación con los mecanismos económicos del territorio.

PALABRAS CLAVE: Asturias, villas marítimas, familia, sectores profesionales, Catastro de Ensenada.

ABSTRACT: The region of Asturias, situated in the north east of the Iberian Peninsula, is administratively divided into 78 counties or municipalities, with the most highly populated of these being found on the coast. During the ancien régime, the geography and climatology of Asturias meant the sea was the main connection for the region. Foods such as cereals arrived at the ports in Gijón and Avilés which allowed for the demographic development of both these cities and other «smaller» seasisde towns ahead of the rest of the region.

In central Asturias, many counties combined the resources that the sea had to offer with agriculture, turning their towns into satellites for the big ports. This is the case for Candás, the capital of the county Carreño, which was recognised as an important whaling port during the $16^{\text {th }}$ century and was very wellknown in northern Europe. The industry of processing fishing products, which lead to the creation of canning factories in the $19^{\text {th }}$ century, allowed the county a certain autonomous survival in comparison to larger councils, avoiding both demographic and economic decline. In the mid- $18^{\text {th }}$ century, the Ensenada cadastre gave a population of 985 which included surgeons, notaries, various landlords, an elementary school teacher, women who kneaded bread, farmworkers and many other professions related to the fishing industry and this study is vital in understanding the sociology of the municipality.

In this paper, the aim is to provide a photograph of a specific year in the $18^{\text {th }}$ century, 1752-53. We analysed the county's family structures and labour patterns in this year and how it related to the economic mechanism in the region, drawing a comparison between the main rural zones and the urban centre.

KEYWORDS: Asturias, Seaside Towns, Family, Professional Sectors, Catastro de Ensenada. 
Los estudios de la familia como núcleo primigenio de la sociedad, se han puesto de relevancia en la península ibérica en los últimos años, no sólo por el reconocimiento que a esta institución se le ha dado en los distintos países del «mundo occidental», si no porque se ha evidenciado la importancia que la familia ha tenido en la configuración de la sociedad actual ${ }^{1}$. Para estas investigaciones, se hacen imprescindibles las investigaciones locales, investigaciones que han permitido, partiendo de la aplicación del sistema de clasificación de familias laslettiano, distinguir entre una región de predominio de familia troncal al norte de la península ibérica y otra de familias nucleares al centro y el sur².

En Asturias, las aportaciones particulares que relacionan históricamente la familia con su contexto socio-profesional son escasas, y suelen incidir en la presencia de una troncalidad dominante en el Antiguo Régimen ${ }^{3}$.

Aunque, en este caso, sólo contamos con una instantánea de un año concreto de mediados del siglo XVIII, creemos que constituye igualmente un referente interesante que contribuirá a construir el mapa socio-familiar de la Asturias de la Edad Moderna.

\section{UN RINCÓN DE HOJAS Y HIERBAS}

Las peculiaridades geográficas asturianas, al norte el mar cantábrico y al sur la cordillera cantábrica con los Picos de Europa, favorecen una serie de subdivisiones territoriales a medida que el paisaje se acerca más o menos al mar, distinguiendo entre los concejos de montaña, los de interior y los de costa, cada uno de ellos con su propia idiosincrasia. De los veintiuno concejos que comprenden el litoral asturiano, sólo los del centro, aportan el $37,7 \%$ del monto total de la población, conformando pues un conjunto de importancia demográfica notable. Es en esta franja costera donde se halla Carreño, con una superficie de $66,70 \mathrm{Km}$ cuadrados y que alberga en la actualidad una población de 11.000 habitantes de los que el 66\%

${ }^{1}$ VV.AA. (2011): Familias. Historia de la sociedad española (del final de la Edad Media a nuestros días). Madrid, Cátedra, pp.10-12.

${ }^{2}$ Ibídem, pág. 28.

3 A este respecto, Florentino López esboza un panorama general en El grupo doméstico en la Asturias del siglo XVIII, y de forma particular contamos con el artículo de Roberto García Morís, " ¿Labradores o herreros? La familia campesina en el concejo asturiano de Taramundi», Alberto Morán Corte y Patricia Suárez Álvarez, «Familia y hogar en Asturias a mediados del siglo XVIII: el caso del concejo de Castrillón» o Alberto Morán Corte, «Estructuras familiares y medios de vida en la Europa atlántica del Antiguo Régimen: el ejemplo de Villaviciosa», trabajo este último inédito presentado al II Encontro do CITCEM en Oporto. Igualmente, el presente trabajo ha sido presentado como comunicación al mismo encuentro. 
se concentra en su capital, la villa de Candás. Internamente, está dividido en doce parroquias de las que sólo cuatro son costeras, (Candás, Perlora, Albandi y Carrio) aunque la cercanía del resto y la suave orografía del concejo hacen que las más interiores mantengan estrechos vínculos con la mar.

Durante la Edad Media, el municipio estuvo bajo la órbita de influencia del Castillo de Gauzón, formando parte de su alfoz, territorio subordinado a otro principal administrativamente, que en 1309 pasó a depender de la villa de Avilés por concesión de Fernando IV.Se sabe que ya en el siglo XVI, Carreño contaba con representación en la Junta General del Principado de Asturias por lo que se deduce que por esas fechas, ya estaba independizada de la villa de Avilés. Sin embargo, habrá que esperar a finales del siglo XVII para encontrarnos con las primeras Ordenanzas Municipales, que regularán, entre otros asuntos, el mercado dominical. En el siglo XVIII tomó también parte activa en un momento clave de la vida política española, la Guerra de Sucesión, en la que se distinguió por su ayuda y lealtad al Borbón, que premió al concejo con el título de «Fiel».

Respecto a su economía, se tienen noticias de la dedicación a la pesca ballenera desde el siglo XIII, práctica que les llevaría hasta las costas de Irlanda, en cuyos mares, según la leyenda, habrían encontrado el símbolo de la villa a partir del siglo XVI, el Cristo de Candás formó parte ${ }^{4}$.

A Carreño, Clarín lo describiría como un rincón de hojas y hierbas, rincón que, como si de una fotografía se tratase, hemos intentado describir en unas fechas concreta de su historia, los años centrales del siglo XVIII ${ }^{5}$.

Para realizar esta «fotografía» hemos tomado como fuente principal el censo fiscal realizado a mediados del Setecientos en Castilla, y que se conoce con el nombre de Catastro de Ensenada.

\section{LA FUENTE PARA NUESTRO ESTUDIO: EL CATASTRO DE ENSENA- DA EN ASTURIAS}

El Catastro del Marqués de la Ensenada formaba parte del proyecto de reforma fiscal, que, bajo el reinado de Fernando VI (1713-1759), intentó implantarse sin éxito en la corona castellana. El nombre dado al corpora documental responde a su artífice, don Zenón de Somodevilla y Bengoechea, que después del Real Decreto de 10 octubre de 1749 y tras un intenso debate sobre «cómo y dónde» debía

\footnotetext{
${ }^{4}$ VV.AA. (2007): Carreño. El libro del concejo, Avilés, Azucel.

${ }^{5}$ Coletes Blanco, A. (1995): Un rincón de hojas y hierbas. Candás y el concejo de Carreño en la vida y obra de Leopoldo Alas Clarín, Candás, Centro de escultura de Candás Museo Antón.
} 
implantarse, procedió a realizar el catastro en las 22 provincias castellanas. Las averiguaciones se desarrollaban en dos niveles, el municipal, cuyas informaciones se obtendrían a través de las respuestas a 40 preguntas relativas al municipio (Respuestas Generales), y el individual, donde declararían sus riquezas cada una de las personas jurídicas seglares y eclesiásticas (Libro de Hacienda), de las que previamente se habría registrado su situación personal y profesional (Libro de lo Personal). Este segundo conglomerado de información es lo que se conoce con el nombre de Respuestas Particulares del Catastro de Ensenada ${ }^{6}$.

En Asturias, perteneciente a la provincia de León, pero separada de ésta para realizar el catastro por decisión de la Real Junta de Única Contribución en 1751, se efectuaría por cotos y concejos, aunque dentro de estos, en ocasiones, también se establecería una subdivisión por parroquias.

Tras una primera operación piloto en el pueblo de Pajares, en agosto de 1751, las indagaciones comenzarán a ser continuadas en otoño, empezando la actuación por el Coto de Cerdeño, y concluyéndose tres años después, no sin conflictos ${ }^{7}$.

El concejo de Carreño comenzó a catastrarse en una sola operación en noviembre de 1752 de la que, a día de hoy, sólo se conservan los libros de seglares, que constituirán la fuente principal de nuestra comunicación.

\section{LA COYUNTURA DEMOGRÁFICA EN CARREÑO EN 1752}

Para entender la instantánea que nos proporciona el catastro, merece la pena dar unas breves coordenadas sobre la coyuntura demográfica de la Asturias de la primera mitad del siglo XVIII.

A principios de la centuria, el Principado se vio azotado por una recesión demográfica sin parangón. El año de 1709 fue el primero de una serie de años en que los asturianos (al igual que el resto de los europeos) tuvieron que hacer frente a un crudo invierno que provocó una serie de malas cosechas, trayendo consigo hambrunas y enfermedades. Sin apenas tener tiempo de recuperarse de los últimos problemas con los que se despidió el siglo XVII, Asturias tuvo que hacer frente a la que sería la última gran crisis de la modernidad, en la que las cifras de defunciones

${ }^{6}$ CAmarero Bullón, C. (2002): «El Catastro de Ensenada 1749-1759, diez años de intenso trabajo y 80.000 volúmenes manuscritos», CT: Catastro, $\mathrm{n}^{\circ} 46$, Madrid, Dirección General del Catastro.

7 Manzano Ledesma, F. (2010): «Las operaciones catastrales en el Principado de Asturias (1751-1754) o cómo usar del pan y del palo», Las Respuestas Generales del Catastro de Ensenada en el Principado de Asturias, Oviedo, Real Instituto de Estudios Asturianos. 
se sextuplicaron. No obstante, nunca se volvió a sufrir una crisis de tal envergadura, alcanzando a partir de 1725 un crecimiento global del $60 \%{ }^{8}$, a pesar de las constantes interrupciones de hambrunas y enfermedades. El concejo de Carreño no fue ajeno al invierno europeo, lamentando unas cuotas de defunciones sin parangón en todo el siglo XVIII, a las que sólo se asemejarían las fechas de grandes naufragios.

Casi medio siglo después, la coyuntura regional favorecía una prosperidad demográfica de la también participaba nuestro concejo. Atrás habían quedado las terribles secuelas de la citada hambruna, las epidemias de finales de los años 30 , que habían afectado sobremanera al campo, y las fiebres ictéricas de los años 40 que no tuvieron la repercusión catastrófica que se esperaba en Carreño 9 .

Gráfico 1. Defunciones en Carreño a lo largo del siglo XVIII

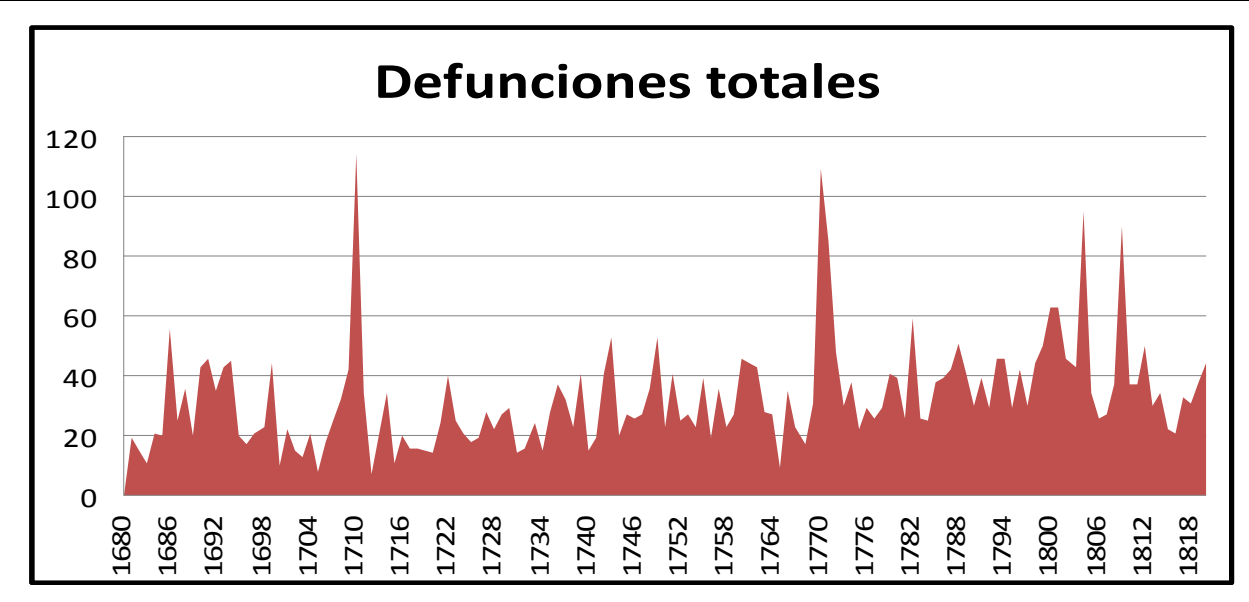

FUENTE: A.D.O. Libros de defunciones de la parroquias de Santiago de Ambás, Santa María de Logrezana, San Salvador de Perlora, Santa María del Piedeloro y San Félix de Carreño.

La introducción del maíz, que ya por estas fechas habría desplazado al panizo y al mijo de entre los cultivos más populares en Asturias en las parroquias de marina y valles precosteros, unido a la diversificación alimenticia que aportaba el pescado,

${ }^{8}$ Ansón CALvo, M.C. (1985): «Contribución al estudio de la demografía histórica en Asturias durante los siglos XVII y XVIII», Población y sociedad en la España cantábrica durante el siglo XVII, Santander, Institución cultural de Cantabria, pág. 104.

${ }^{9}$ Ibidem, pp. 95-111. 
optimizó el despegue demográfico de los concejos marítimos, y por ende, de nuestra villa y su territorio ${ }^{10}$.

Gráfico 2. Comparativa ámbito rural / semiurbano de las series de defunciones

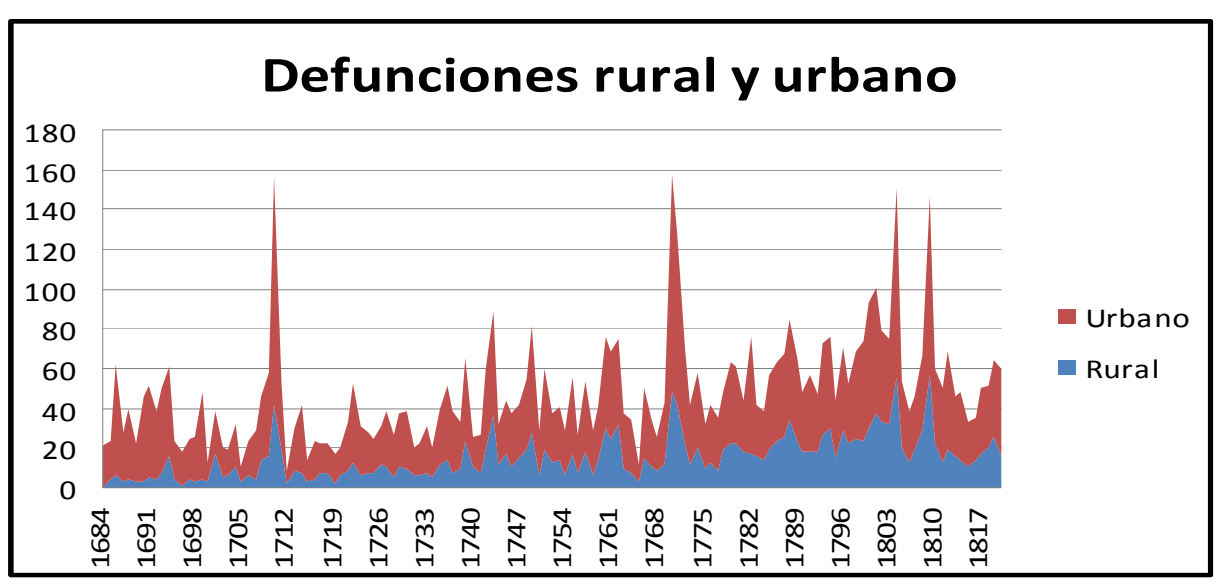

FUENTE: A.D.O. Libros de defunciones de la parroquias de Santiago de Ambás, Santa María de Logrezana, San Salvador de Perlora, Santa María del Piedeloro y San Félix de Carreño.

A mediados del siglo XVIII, el 41,5\% de la población se aglutinaban en las parroquias de Candás y Perlora, ésta segunda lindante con la de la villa y en estrecha relación con la capital. Solamente la villa, proporcionaba el $28,6 \%$ del total de la vecindad así como un abanico socio-profesional diverso ${ }^{11}$.

10 Anes y Álvarez De Castrillón, G. (1977): «Edad Moderna II. El Antiguo Régimen: economía y sociedad» Historia de Asturias, vol. II, Vitoria, Ayalga, pág. 66.

${ }^{11}$ Para realizar nuestro estudio hemos aplicado el coeficiente conversor 4, obtenido en Castrillón a partir de los datos extraídos del Catastro de Ensenada, y a medio camino del que Martín Galán da para la península ibérica por esas fechas, de 3,8, y del proporcionado por Gonzalo Anes para Asturias de 4,6. Ver Morán Corte, A. y SuÁrez Álvarez, P. (2010):«Familia y hogar en Asturies a mediados del siglo XVIII: el caso del concejo de Catrillón»,Família pagesa i economía rural. VII Congrés sobre sistemes agraris, organització social i poder local, Lleida, Institut d'Estudis Ilerdencs, MARTín GALÁN, M. (1985):«Nuevos datos sobre un viejo problema: el coeficiente de conversión de vecinos en habitantes», Revista de Internacional de Sociología, Madrid, Centro Superior de Investigaciones Científicas y ANES Álvarez De CASTRILlón, G. (1988): Economía y sociedad en la Asturias del Antiguo Régimen, Barcelona, Ariel. 
El 94,6\% de las gentes de Carreño tenían la condición de hidalgo, un 3,3\% eran pecheros y un $1,9 \%$ declaraban estar en posesión de hidalguía pendiente de demostración. La condición de hidalgo en la Asturias del XVIII no era algo exclusivo de una minoría si no más bien al contrario. En la segunda mitad de la centuria, podemos hablar, según Gómez Álvarez, de «una cierta universalización de la condición de hidalgo» con porcentajes que superaban el $90 \%$, dentro de los cuales, se podían distinguir a los Hidalgos Notorios o de Casa y Solar Conocido ${ }^{12}$.

Gráfico 3. Distribución Social en Carreño

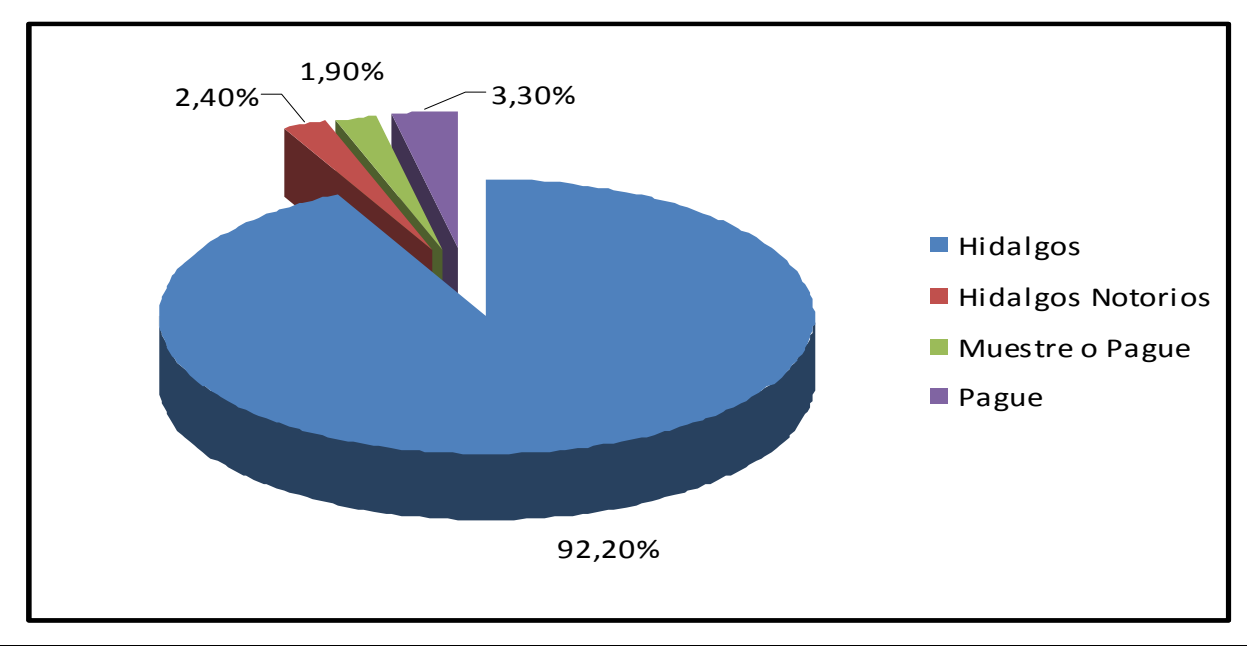

FUENTE: A.M.C. Padrones de Moneda Forera. Padrón del año 1751.

De estos porcentajes resulta llamativo que no observásemos ningún pechero en el ámbito rural y que los hidalgos notorios se concentrasen en mayor medida en la villa, aunque el status de Don, fuese otorgado casi al 50\% entre personalidades destacadas del campo y de la capital.

La villa de Candás, con aproximadamente 1.084 habitantes en 1751, se asemejaba a las pequeñas villas marineras que Isidro Dubert catalogó en la Galicia cantábrica y occidental ${ }^{13}$, con características propias que la situaban a medio

12 Gómez Álvarez, U. (1993): La sociedad tradicional asturiana, Oviedo, Universidad de Oviedo, pp. 14-15.

13 DuBERT, I. (2002): «Las dinámicas demográficas de las pequeñas villas gallegas a finales del Antiguo Régimen», Obradoiro de Historia Moderna, $\mathrm{n}^{\circ} 11$, Santiago de Compostela, Universidad de Santiago de Compostela, pp. 64-71. 
camino entre el campo y la semiurbanidad. En 1753, y según el Catastro de Ensenada, su puerto tenía catastradas dieciocho embarcaciones de «pescar sardina, besugo y otros peces» y dos pinazas que hacían tres viajes a Bilbao al año, las cuales, reportaban al Gremio de Mareantes más de 40.000 reales anuales. La villa tenía asimismo dieciocho mercaderes, un estanco, dos tabernas, dos cirujanos, un hospital de peregrinos bajo el patronato de Santiago y contaba dos escribanos, un fiel de aduanas, varios arrendatarios de rentas públicas, un procurador y un alcalde ordinario. Candás funcionaba así como centro neurálgico de las parroquias rurales colindantes, que en algunos casos, se fusionaban con el propio núcleo semiurbano.

Por su parte, el mar funcionaba como agente activo de la vida de la capital estando, el $47 \%$ de los oficios catastrados, ligados a la explotación de este recurso.

\section{ESTRUCTURA FAMILIAR A MEDIADOS DEL SIGLO XVIII}

La familia como núcleo primigenio de la sociedad es el primer componente del Carreño del XVIII que hemos decidido analizar recurriendo, como es habitual, al clásico esquema laslettiano.

Cuando Peter Laslett inició su investigación sobre el pensamiento de John Locke nada hacía presagiar que revolucionaría las investigaciones sobre la Historia de la Familia, al ponerse en contacto con los libros parroquiales de la localidad de origen del autor. Fechados a mediados del siglo XVII, pudo comprobar como la tipología familiar que predominaba en el condado de Nottinghamshire era la nuclear, esto es, la conformada por padre, madre e hijos, viniendo a contradecir a la historiografía tradicional inglesa que mantenía que la familia preindustrial británica se caracterizaba por su troncalidad. Fruto de esta hipótesis, planteada en The World we have lost, nació el sistema de clasificación de familias Hammel-Laslett, vigente en la actualidad ${ }^{14}$.

En Asturias esta clasificación estaría plenamente aceptada, aunque en ocasiones, la complejidad que presentan los hogares asturianos, harán susceptibles ciertas modificaciones. En anteriores investigaciones, y basándonos en el artículo de Spike \& otros, Si todo el mundo fuera Inglaterra: la teoría de Peter Laslett sobre la composición de los grupos domésticos vs. la realidad tapatía, 1821-1822,

\footnotetext{
${ }^{14}$ Moll Blanes, I. (2008):«Peter \& Laslett: Contexto y aportación (1915-2001)», La Historia de la familia en la península ibérica (siglos XVI-XIX), Cuenca, Universidad de Castilla La Mancha, pp. $29-40$.
} 
planteamos así dos nuevos subtipos que nos permitieron adaptar la realidad de los fuegos de Asturias a la tipología de Laslett ${ }^{15}$ (CUADRO 1):

Con familia extensa combinada hemos hecho referencia a aquellos hogares formados por un núcleo primigenio y una serie de agregados de difícil clasificación que conviven bajo el mismo techo, mientras que en familia múltiple relacionada colateralmente hemos agrupado a los hogares formados por dos núcleos familiares relacionados de forma colateral - por ejemplo, una familia nuclear cuyo titular sería hermano o hermana del titular de otro núcleo familiar- conducta en ocasiones habitual en el campo asturiano, aunque en Carreño no hemos hallado un hogar con tales características.

Cuadro 1: Clasificación de las estructuras familiares ${ }^{16}$

\begin{tabular}{|c|c|}
\hline Tipos & Subtipos \\
\hline 1. Solitarios & $\begin{array}{l}\text { 1.a. Viudo/a } \\
\text { 1.b. Soltero/a }\end{array}$ \\
\hline 2. Sin estructura familiar & $\begin{array}{l}\text { 2.a. Hermanos copresidentes } \\
\text { 2.b. Corresidentes con otro parentesco } \\
\text { 2.c. Corresidentes sin aparentes lazos de parentesco }\end{array}$ \\
\hline 3. Familia nuclear & $\begin{array}{l}\text { 3.a. Matrimonio sin hijos } \\
\text { 3.b. Matrimonio con hijos } \\
\text { 3.c. Viudo con hijos } \\
\text { 3.d. Viuda con hijos }\end{array}$ \\
\hline $\begin{array}{l}\text { 4. Familia extensa (Un núcleo } \\
\text { familiar más parientes) }\end{array}$ & $\begin{array}{l}\text { 4.a. Ascendente (pariente de la generación anterior) } \\
\text { 4.b. Descendente (pariente de la generación posterior) } \\
\text { 4.c. Colateral } \\
\text { 4.d. Ascendente y colateral } \\
\text { 4. e. Sin determinar } \\
\text { 4. f. Familia extensa combinada }\end{array}$ \\
\hline $\begin{array}{l}\text { 5. Familia múltiple (Dos núcleos } \\
\text { familiares emparentados) }\end{array}$ & $\begin{array}{l}\text { 5.a. Unidad secundaria ascendente } \\
\text { 5.b. Unidad secundaria descendente } \\
\text { 5.c. Otros tipos } \\
\text { 5.d. Familia múltiple relacionada colateralmente }\end{array}$ \\
\hline
\end{tabular}

Pero ¿qué entendemos por término hogar? Según el Diccionario de Autoridades

15 Spike, T., HARrington, L., \& HARrington M. (2007): «Si todo el mundo fuera Inglaterra: la teoría de Peter Laslett sobre la composición de los grupos domésticos vs. la realidad tapatía, 18211822», Estudios Sociales Nueva Época, 2, Guadalajara, Universidad de Guadalajara, pp. 35-36.

16 Morán Corte, A. y SuÁrez Álvarez, P. (2010):«Familia y hogar en Asturies...», pp. 383403. En negrita los subtipos propuestos por los autores. En el caso de Carreño, no hemos encontrado ningún fuego susceptible de clasificar como 5.d. 
hogar es «el lugar donde se enciende la lumbre o fuego para el servicio ordinario de una casa. Tomase también por la casa u domicilio Antiguamente, se decía fogar, y uno y otro viene del latino focus, que significa esto mismo» ${ }^{17}$, es decir el espacio de habitación de un grupo de individuos, que no necesariamente guardaban una relación de consanguinidad, tal como refleja otro de los axiomas de Autoridades en 1732, cuando describe familia como «la gente que vive en una casa debaxo del mando del señor de ella [...] $\rangle^{18}$. Esta definición cobra si acaso más importancia en el caso de Asturias, donde, tradicionalmente, se mantenía, al igual que en la historiografía inglesa anterior a Laslett, que la familia troncal era la predominante en la época preindustrial ${ }^{19}$. En este sentido, López Iglesias propone un panorama distinto con una clara tripartición entre la Asturias central y oriental, con tasas de nuclearidad de más del $80 \%$, la Asturias occidental, con elevados porcentajes de familias complejas, y las villas asturianas, donde aumentan los hogares solitarios ${ }^{20}$.

En el caso de nuestro concejo situado, como ya se dijo, en la zona central, podemos decir que esta teoría se cumple, siendo, la estructura familiar resultante, la que refleja el CUADRO 2.

Efectivamente, el $77,4 \%$ de los hogares carreñenses estaban dentro de los parámetros de la nuclearidad, con la forma de matrimonio con hijos la más popular, con un $56,7 \%$ sobre el total. Esta cifra se halla muy en consonancia con la del concejo vecino de Castrillón, de un $74,4 \%$ y someramente alejada del de Villaviciosa, en el oriente asturiano, con un $69,9 \%$ de familias nucleares ${ }^{21}$.

Dentro de este grupo, le sigue en importancia porcentual el grupo de matrimonios sin hijos, 3.a, donde los cabezas de familia declaraban tener menos de 30 años en un $46,7 \%$ de los casos, entre 30 y 50 en un $25,2 \%$, y más de 50 en un $28,1 \%$. En una región donde la edad media de acceso al matrimonio rondaba los

${ }^{17}$ Diccionario de Autoridades, año de 1734.

18 Ibidem, año de 1732.

${ }^{19}$ Varios son las monografías donde se pone de manifiesto esta teoría, por citar algunas: GARCíA MARTíNEZ, A. (2004): «La casería tradicional asturiana», Los asturianos, raices culturales y sociales de una identidad, Oviedo, pp.-162-180; Antropología de Asturias (2008), Oviedo, KRK, pp. 276-313; CABAL C. (1992): La familia, la vivienda y los oficios primitivos, Oviedo, GEA.

${ }^{20}$ LÓPEZ Iglesias, F. (1999): El grupo doméstico en la Asturias del siglo XVIII, Oviedo, Real Instituto de Estudios Asturianos, pág.87.

${ }^{21}$ Para Castrillón ver MorÁn Corte, A. y SuÁrez Álvarez, P. (2010): «Familia y hogar en Asturies...» y para MORÁN CORTE, A. (Inédito): «Estructuras familiares y medios de vida en la Europa atlántica del Antiguo Régimen: el ejemplo de Villaviciosa». 
26,61 años para las mujeres y los 26,92 para los hombres ${ }^{22}$, la primera cifra nos pondría tras la pista de matrimonios jóvenes que aún no habrían tenido descendencia, mientras que la franja de titulares mayores de 50 años tendría ya a sus hijos fuera del hogar. De los otros dos subtipos, hay que decir que predominaba el de las mujeres viudas con hijos, un $8 \%$, frente a sus homólogos masculinos, con un $2,1 \%$ del total de los casos catastrados, situación ésta a la que volveremos más adelante.

Cuadro 2. Estructura familiar pormenorizada en Carreño

\begin{tabular}{cc}
\hline Tipo & $\%$ \\
\hline $1 . \mathrm{a}$ & 6,3 \\
$1 . \mathrm{b}$ & 3,96 \\
$2 . \mathrm{a}$ & 0,81 \\
$2 . \mathrm{b}$ & 0,4 \\
$2 . \mathrm{c}$ & 0,1 \\
3.a & 10,88 \\
3.b & 56,74 \\
3.c & 2,13 \\
3.d & 8,03 \\
$4 . \mathrm{a}$ & 3,56 \\
$4 . \mathrm{b}$ & 2,95 \\
$4 . \mathrm{c}$ & 1,11 \\
$4 . \mathrm{d}$ & 0,4 \\
4.e & 1,32 \\
4.f & 0,61 \\
5.a & 0,1 \\
5.b & 0,5 \\
\hline
\end{tabular}

El tipo 1 de hogares solitarios está en consonancia con la media regional, con un $10,2 \%$ de fuegos de este tipo, de los que cabe destacar que un $82 \%$ estarían encabezados por mujeres. Nuevamente las mujeres solas al frente de un hogar, bien con hijos o sin ellos, aparecen en superioridad numérica frente a los hombres, siendo las primeras titulares de un $18,8 \%$ de los fuegos, mientras que los segundos lo harían en un $4,7 \%$ de los casos. Este hecho, vendría a refrendar la teoría de que los hombres, bien en viudedad bien soltería, tenían más oportunidades en el mercado matrimonial asturiano ${ }^{23}$.

22 AnSÓn CALvo, M.C. (1992): Asturias en 1787 según los datos del censo de Floridablanca, Oviedo, Universidad de Oviedo, pág. 105.

${ }^{23}$ LÓpez IgLESIAS, F.(1999): El Grupo Doméstico... pp.114-116 
Los hogares sin estructura familiar representaban un exiguo 1,3\% del total, por debajo de las cifras que López Iglesias da para las ciudades asturianas, con un $5,7 \%$, y de las campesinas, tanto del centro-oriente como del occidente, también con porcentajes en torno a un $5 \%{ }^{24}$.

Al igual que sucede en otras zonas, dentro del tipo 2, la tipificación más habitual es la de hermanos corresidentes, siempre en familias de dos, que en un $66,6 \%$ son mujeres.

La familia extensa representa en Carreño un 9,95\% del resultado del recuento de los fuegos, similares a los resultados encontrados en los concejos marítimos ya comentados, Castrillón, 9,83\%, y Villaviciosa, 9,32\%. Si lo comparamos con el resto de la cornisa cantábrica, vemos cómo la cifra de complejidad, es decir, la suma de las familias extensas y las múltiples, son menores que las que algunos autores dan para los núcleos de dominio de familia troncal, tanto en Galicia y Cantabria, con un mínimo de un 18\% de troncalidad para considerar la región de estudio como de predominio troncal, como en la zona vasco-navarra, donde se establece un umbral de complejidad del $30 \%{ }^{25}$.

Del subtipo 4.a, clasificación dada a aquellas familias donde junto al núcleo familiar conviven uno o varios parientes de la generación anterior, podemos decir que la norma suele darse en familias labradoras de estructura nuclear, mientras que cuando es un pariente de la generación posterior el que pasa a formar parte de la unidad familiar, subtipo 4.b, la realidad se torna un poco más compleja. Ya no se tratan de cabezas de familia, generalmente hombres, que mantienen a uno de sus padres o suegros por «hallarse imposibilitado» o ser «de avanzada edad», si no que en un tercio de los casos, los sobrinos y/ o nietos proporcionan una fuerza de trabajo extra a aquellas familias que no tienen hijos en la casa. No es de extrañar así que este tipo se observe también, en buena medida, en caserías cuya economía giraban entorno al campo.

Del mismo modo, los agregados del subtipo 4.c, hermanos y / o cuñados del titular, también aportaban brazos extra para las labores del campo, y en los casos en los que el oficio principal es el de artesano, los hermanos están reseñados como oficiales del taller de el / la cabeza de familia. Cuando la soltería del hermano se

${ }^{24}$ Ibídem, pág. 117.

25 Ambos datos en PÉrez García, J. M. (2008): «Familias y hogares en Galicia y en la cornisa cantábrica durante el Antiguo Régimen» y Erdozain AzPilicueta, P. y Mikelarena PeÑa, F. (2008): «La historia de la familia en el País Vasco y Navarra. Un balance», La Historia de la Familia en la Península Ibérica (siglos XVI-XIX), Cuenca, Universidad de Castilla La Mancha. 
perpetuaba, estaríamos ante la figura del «tión», tipificado en Asturias como hermano «solterón» que ayuda en las faenas agrícolas por apenas la comida y el vestido $^{26}$.

En contadas ocasiones, además del hermano vive con el núcleo familiar la madre o padre del titular conformando así lo que sería el 0,4\% del subtipo 4.d.

Hemos agrupado en subtipo 4.d a aquellos casos en los que no se especifica qué parentesco tienen los agregados mencionados con el titular. Casi la mitad de estas familias han acogido a huérfanos menores de edad y en otros casos, los parientes en los que a priori no se aprecian lazos de consanguinidad, son mayores de 60 años. El hecho de que esta estructura se dé en familias trabajadoras del campo o cuyos titulares estén catastrados sin oficio deja entrever aquí los lazos de solidaridad vecinal en las comunidades rurales, que al contrario que podía ocurrir en los núcleos urbanos, resultaban un entorno más confortable ante las situaciones adversas.

En familia extensa combinada incluimos a aquellos hogares en los que conviven parientes colaterales con los de grado ascendente y/o descendente. Dos nietos y una tía convivían con Pedro Cuervo, su mujer y sus hijos, mientras que bajo el techo de Don Rodrigo Alonso Villar moraban su mujer, sus hijos, dos hermanos capellanes y un sobrino. La residencia de los sobrinos en los hogares asturianos se mostraba así habitual, máxime en el mundo rural, donde frecuentemente aparecían reseñados como criados del cabeza.

En lo que toca a la estructura de familia múltiple, sólo un $0,6 \%$ del total son fuegos ocupados por dos núcleos familiares emparentados, siendo más frecuente la forma en que los hijos casados pasan a tener su domicilio en el de los padres, tipo que se daba fundamentalmente en familias campesinas

\section{LA ESTRUCTURA PROFESIONAL}

Si hay algún sector en el que se hace patente la dicotomía campo-mar en el concejo de Carreño, este es sin duda, en el área profesional.

De las 1283 personas que se hallan catastradas con alguna profesión, contabilizando titulares, cónyuges de titulares e hijos, no es de extrañar, dado el carácter rural de la mayor parte de sus parroquias, que el $72,1 \%$ de las profesiones fuesen copadas por labradores u oficios relacionados con el campo. Aquí, hemos incluido, además de a aquellos que señalaban su oficio como el de labrador o

\footnotetext{
${ }^{26}$ MorÁn Corte, A. y SuÁrez Álvarez, P. (2010):«Familia y hogar en Asturies...», pág 395.
} 
trabajador del campo, a aquellos que guardaban relación con la explotación directa de la tierra, esto es, molineros y panaderas, aunque estas últimas bien podrían ser catalogadas en el sector servicios ${ }^{27}$. De éstas, cabe decir que en nuestro concejo es un oficio exclusivamente femenino, y que las mujeres casadas, eran todas ellas panaderas boroñeras o de maíz y formaban un binomio profesional con su cónyuge labrador. El mismo binomio se documenta en los casos en que los oficios de molinero aparecen como segunda profesión $(8,2 \%$ del total de pluriempleados) donde exceptuando un titular, el resto compaginaban la labranza con la transformación de los cereales que recolectaban.

Gráfico 4. Estructura profesional en Carreño

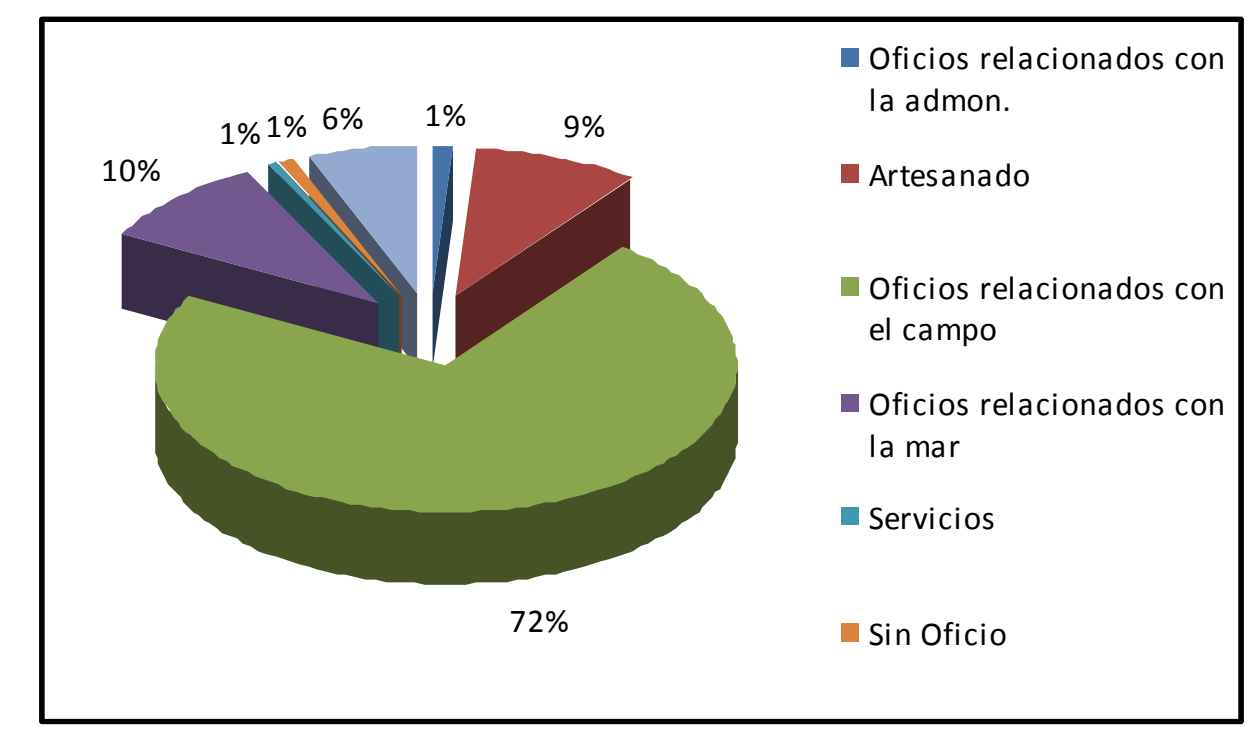

FuenTE: A.M.C. Respuestas Particulares del Catastro de Ensenada. Libro de Seglares.

${ }^{27}$ En la relación de sectores profesionales que presentamos al XXXI Encontro da Aphes en la comunicación «Actividades profesionales y desarrollo económico en el norte de la Península Ibérica: un acercamiento a la sociedad preindustrial asturiana», englobamos esta actividad en el sector servicios, aunque en esta ocasión he querido ligarla a los oficios ligados al campo para distinguirla de los oficios que conllevaban un servicio y/o atención específica al público y que se daban fundamentalmente en ámbito urbano. SuÁrez Álvarez, P. y Morán CorTe, A. (Inédito) «Actividades profesionales y desarrollo económico en el norte de la Península Ibérica: un acercamiento a la sociedad preindustrial asturiana», comunicación presentada al XXXI Encontro da Aphes, Coimbra, 2012. 
Un $8 \%$ de los vecinos que declaraban algún empleo no se dedicaban a él en exclusividad. De estos, un $89 \%$ tenían dos empleos, un $6,8 \%$ se empleaba en tres, un $1,3 \%$ declaraba cuatro ocupaciones y un $2,7 \%$ incluso cinco oficios.

Para realizar nuestra clasificación no hemos tenido en cuenta estas segundas dedicaciones, por lo que al más del $70 \%$ de oficios en torno al campo le seguiría un $9,8 \%$ de trabajos relacionados con la mar. En este sector, cabría hacer una clasificación interna entre mercaderes y comerciantes de sobremar -a los que también encasillamos en otra ocasión dentro del sector servicios- los marineros matriculados y el resto de los oficios que tendrían relación con las actividades marítimas, y que por regla general, también irían ubicados dentro de otros ramos profesionales como puede ser de nuevo el sector servicios, en el caso de las escabecheras. Este último oficio, también típicamente femenino, aparece copado en el Catastro por las mujeres casadas, con excepción del caso de Ana García Barrera, viuda de 60 años.

A los trabajos de la mar, les sigue en una importancia, con una corta distancia, $9,1 \%$, el porcentaje de vecinos a los que englobamos entre los artesanos. Los oficios típicos que existían en la Asturias rural, zapatero, sastre, tejedor/a, coexistían otros más característicos de una sociedad urbana o semiurbana o que demandaban una especialización económica determinada. Así, tallistas, toneleros, un gran número de herreros y canteros, cesteros, carpinteros y calafates o carpinteros de rivera son algunos de los oficios que nos aparecen catastrados y que guardaban relación con las actividades que se desarrollaban en la villa marítima de Candás. El entramado social de los gremios de artesanos proporcionaba dentro de un mismo oficio un status diferenciador entre maestros, generalmente dueños de los talleres, oficiales y aprendices, teniendo éstos últimos más características en común con los criados que con los trabajadores del oficio. Las únicas titulares que aparecen como tratantes, las hemos agrupado aquí también en razón al producto con el que trajinan, el lino.

Otro rasgo de «urbanidad» lo aportaría el número de oficios públicos ligados a la administración, con un 1,2\% de ocupaciones sobre el total. El concejo contaba con ocho regidores, tres escribanos, tres arrendatarios, un juez ordinario y un fiel de aduanas, recuento que parece a priori nimio pero que nos está informando de que no estamos ante un territorio exclusivamente rural ${ }^{28}$.

28 Del recuento realizado sobre trece concejos de la franja central asturiana, los de Avilés, Oviedo, Gijón, Villaviciosa, Carreño, Cabranes y Proaza, tenían vecinos con cargos en la administración pública. Los tres primeros son los núcleos urbanos más importantes en la Edad Moderna, Villaviciosa y Carreño son dos concejos encabezados por villas marítimas, y Cabranes y 
La adjudicataria sobre un vecino le dotaría de prestigio y relevancia social, características que seguramente tuvieran los titulares a los que catalogaron sin oficio. El 0,9\% que representa este grupo, nos está informando de un grupo social que podría mantenerse de sus rentas y por ende, económicamente poderoso.

El sector servicios resulta porcentualmente escaso en el concejo de Carreño al incluir únicamente a aquellos cabezas que señalaban las profesiones en las que se presta un servicio a la comunidad, bien lúdico bien de necesidad, como primer oficio. De ahí que sólo el $0,6 \%$ de los oficios catastrados correspondan a mercaderes de tienda abierta, mesoneros, taberneros, maestros y cirujanos. Los estanquilleros de tabaco, presentes en toda la geografía profesional asturiana junto con los vendedores de vino o taberneros, compartían en un $75 \%$ su oficio con el de labrador, mientras que algunos artesanos también hacían sus incursiones en el sector servicios como mesoneros y taberneros.

Finalmente, hemos comprendido en el apartado de otras profesiones a aquellos de los que tenemos un único ejemplo inclasificable dentro de los anteriores como puede ser un soldado, dos capellanes en incluso un pobre de solemnidad, casi un oficio en la Asturias del siglo XVIII.

A pesar de no ser un oficio registrado para titular alguno, podemos dar unas breves pinceladas sobre el servicio doméstico a partir de la información obtenida. La media de criados por hogar en nuestro concejo se situaba en un $6,6 \%$, siendo este un oficio paritario, que en un $56 \%$ de los casos sería ejercido por hombres y en un $54,1 \%$ por personas mayores de edad jurídicamente. De todos ellos, un $27,7 \%$ trabajaría por menos de 60 reales, un 58,7\% por un salario entre 60 y 100 reales, un $5,4 \%$ por más de 100 y un $8,7 \%$ no tendría sueldo. En los casos en que los que el salario de los sirvientes estaba por encima de los 100 reales se trataba, excepto en dos ejemplos, de hombres y mujeres mayores de edad y que en ocasiones se les distinguía con un status como puede ser el de «ama de llaves» o «criada de escaleras arriba». Otras veces, familiares menores hacían las veces de servicio doméstico, oficio que también podía ser desarrollado por niños expósitos acogidos en los hogares.

\section{LA SOCIEDAD CARREÑENSE: COMBINACIÓN ENTRE LA ESTRUC- TURA FAMILIAR Y LA ESTRUCTURA PROFESIONAL.}

Llegados a este punto, sobra decir que las relaciones familiares y profesionales

Proaza, concejos que únicamente cuentan con los cargos de regidores, se hallan en el interior y la montaña asturiana respectivamente. 
se hallaban intrínsecamente unidas. No es de extrañar así que en el campo, donde las tareas domésticas demandaban mayor fuerza de trabajo, encontremos un porcentaje más alto de complejidad con un $67,5 \%$ del total de la suma de las familias extensas y múltiples, familias que, en ausencia de hijos, suplían la carencia de brazos para trabajar ${ }^{29}$.

Por otra parte, el hecho de que el $78 \%$ de los titulares sin oficio, fuesen viudas o solteras, en ocasiones acompañadas de otros parientes $(28,5 \%$ de los casos) pero mayoritariamente en solitario, 50,6\%, nos está hablando de una situación de confort económico de las cabezas que en un $15,5 \%$ se traducía también en un status social diferenciador, al precederles el título de doña.

Sí resulta curioso que menos de la mitad de los artesanos catastrados se correspondan con familias con hijos, cuando dichos gremios solían ligar a algún descendiente a su profesión, hecho que sólo ocurre en cinco casos en los que tres maestros canteros, uno carpintero y un maestro sastre que mantienen a sus respectivos hijos como aprendices.

Los cabezas que declararon profesiones ligadas al mar abanderan la nuclearidad y tal vez detrás de esto, estuviese el hecho de que en el 68\% de los cabezas fuesen menores de 50 años. Al igual que en el caso de los artesanos, algunos hijos eligen la profesión del padre para ganarse la vida, otros se decantan por un oficio también ligado al mar, pero menos duro como maestro tallista, y en el caso del hijo de Narciso Torano, marinero matriculado, aprovechan para labrarse un futuro que les facilite la promoción social haciéndose cirujano. Cabe señalar que, dentro de este grupo había que distinguir a los comerciantes de sobremar, cuyas actividades les reportarían mayores beneficios que a los marineros o calafates. No obstante, el bienestar económico no iba necesariamente ligado al estatus social y algunos de los que en este gremio están consignados como dones aparecen como marineros matriculados. Por su parte, la única mujer con este título, doña Clara Suárez Quirós, comerciaba en el Reino de Galicia, mientras que el resto de sus homólogas ligadas a oficios marítimos se ocuparían como sardineras y escabecheras. Si hemos de relacionar la condición social con los sectores profesionales, sería aquí donde abundasen los pecheros, con un 56,6\% del porcentaje total de los no hidalgos trabajando como marineros.

Respecto a la estratificación social dentro de aquellos que cumplían la condición de hidalgo, aunque se ha señalado que el estatus de don precedía a

${ }^{29}$ En el grupo 4.b detectamos que en un $63,3 \%$ de los casos las familias no tienen hijos en casa, por lo que reemplazan a estos por sobrinos o nietos. 
algunos que detentaban cargos administrativos (regidores, arrendatarios, fieles de aduanas) o que no declaraban ningún oficio, no siempre se cumplía esta norma, encontrándonos con dones marineros matriculados y labradores y teniendo que buscar la dicotomía social en las familias rentistas de la zona.

\section{CONCLUSIONES}

Hasta aquí el retrato que el Catastro de Ensenada nos proporciona de la sociedad del concejo de Carreño a mediados del siglo XVIII.

Tras lo observado, podemos concluir que la dinámica familiar del concejo no se distinguiría mucho de la general para el centro asturiano, con un predominio de la familia nuclear sobre el resto de las estructuras y un alto porcentaje de hidalguía. La familia múltiple no traspasaría los umbrales propuestos por algunos autores para la cornisa cantábrica, por lo que se rompe aquí, nuevamente, el mito de la troncalidad de la familia asturiana del Antiguo Régimen.

En algunos casos, la estructura familiar se hallaba estrechamente ligada a la actividad profesional, como en el caso de las familias campesinas demandantes de brazos de trabajo (familias sin hijos o solitarios), actividades profesionales que, cabe señalar, estaban en estrecha unión con los recursos naturales, es decir, con el mar y el campo.

En este sentido, las zonas rurales funcionarían como «alfoz» de la villa y las parroquias como Perlora, ésta última ubicada geográficamente a pié de mar. La villa de Candás por su parte, podría encuadrarse dentro del grupo de villas marítimas semiurbanas que algunos autores proponen, dada su población, diversidad profesional y porcentaje de pecheros.

Respecto a las mujeres, el número de cabezas de fuego que consignan un oficio, $65,6 \%$ sobre el total de féminas titulares, y el número de solitarias, nos pone sobre la pista de lo que Menéndez González denominaría «muyeruca asturiana» ${ }^{30}$, es decir, mujeres cuya capacidad de trabajo extralimitaría el ámbito doméstico y que parece ser podrían valerse por sí mismas de forma independiente. Asimismo, la relación de profesiones ligadas al ámbito femenino, romperían los tópicos de la época, y las mujeres carreñenses trabajarían no sólo en el telar y la fabricación de pan, documentándose también tenderas y tratantes e incluso una comerciante. El hecho de que dos solteras y dos viudas fuesen las únicas cabezas que se ocupaban como tratantes, viene a reafirmar esta teoría de independencia femenina. Por otro

${ }^{30}$ MenÉndez GonZÁleZ, A. (2006): El barranco de las asturianas, Oviedo, KRK, pág. 75. 
lado, las mujeres casadas, trabajadoras del campo aparte, aparecen colaborando con la economía familiar en algunos casos formando binomios profesionales como el de marinero-escabechera ${ }^{31}$.

Todos estos rasgos, aún susceptibles de seguir ahondando en ellos, nos indican que estamos ante un municipio que, a mediados del siglo XVIII, se hallaría a medio camino entre el campo y el mar, con una villa marítima de características semiurbanas y un mundo rural en estrecha relación con la misma.

\section{BIBLIOGRAFÍA}

Anes y Álvarez de Castrillón, G. (1977): «Edad Moderna II. El Antiguo Régimen: economía y sociedad» Historia de Asturias, vol. II, Vitoria, Ayalga.

Anes Álvarez de Castrillón, G. (1988): Economía y sociedad en la Asturias del Antiguo Régimen, Barcelona, Ariel.

AnSÓN CALVO, M.C. (1985): "Contribución al estudio de la demografía histórica en Asturias durante los siglos XVII y XVIII", Población y sociedad en la España cantábrica durante el siglo XVII, Santander, Institución cultural de Cantabria.

Ansón CALVo, M.C. (1992): Asturias en 1787 según los datos del censo de Floridablanca, Oviedo, Universidad de Oviedo

CABAL C. (1992): La familia, la vivienda y los oficios primitivos, Oviedo, GEA.

CAMARERo Bullón, C. (2002):«El Catastro de Ensenada 1749-1759, diez años de intenso trabajo y 80.000 volúmenes manuscritos», CT: Catastro, nº46, Madrid, Dirección General del Catastro.

Coletes Blanco, A. (1995): Un rincón de hojas y hierbas. Candás y el concejo de Carreño en la vida y obra de Leopoldo Alas Clarín, Candás, Centro de escultura de Candás Museo Antón.

Chacón, F, Bestard. J. (dirs.), (2011): Familias. Historia de la sociedad española (del final de la Edad Media a nuestros días). Madrid, Cátedra.

DíAz LóPEz, C. (ed.), (2007): Carreño. El libro del concejo, Avilés, Azucel.

DUBERT, I. (2002):«Las dinámicas demográficas de las pequeñas villas gallegas a finales del Antiguo Régimen», Obradoiro de Historia Moderna, nº11, Santiago de Compostela, Universidad de Santiago de Compostela.

ERdozain AzPilicueta, P. y Mikelarena Peña, F. (2008):«La historia de la familia en el País Vasco y Navarra. Un balance», La Historia de la Familia en la Península Ibérica (siglos XVI-XIX), Cuenca, Universidad de Castilla La Mancha.

GARCİA MARTíNEZ, A. (2004):«La casería tradicional asturiana», Los asturianos, raíces culturales y sociales de una identidad, Oviedo.

García MarTínez, A. (2008), Antropología de Asturias, Oviedo, KRK,

31 Morán Corte, A. y SuÁrez Álvarez, P. (2011): «Más allá del telar: El mundo del trabajo femenino en la Asturias del siglo XVIII» El Futuro del Pasado, 2, Salamanca, pp.495-498. 
Gómez Álvarez, U. (1993): La sociedad tradicional asturiana, Oviedo, Universidad de Oviedo.

LÓPEZ IGLESIAS, F. (1999): El grupo doméstico en la Asturias del siglo XVIII, Oviedo, Real Instituto de Estudios Asturianos.

ManZANo Ledesma, F. (2010): «Las operaciones catastrales en el Principado de Asturias (1751-1754) o cómo usar del pan y del palo», Las Respuestas Generales del Catastro de Ensenada en el Principado de Asturias, Oviedo, Real Instituto de Estudios Asturianos.

MARTín GALÁN, M. (1985):«Nuevos datos sobre un viejo problema: el coeficiente de conversión de vecinos en habitantes», Revista de Internacional de Sociología, Madrid, Centro Superior de Investigaciones Científicas.

MENÉNDEZ GONZÁleZ, A. (2006): El barranco de las asturianas, Oviedo, KRK.

MorÁn Corte, A. y SUÁrez Álvarez, P. (2010):«Familia y hogar en Asturies a mediados del siglo XVIII: el caso del concejo de Catrillón»,Família pagesa i economía rural. VII Congrés sobre sistemes agraris, organització social $i$ poder local, Lleida, Institut d'Estudis Ilerdencs.

Moll BlaneS, I. (2008):«Peter \& Laslett: Contexto y aportación (1915-2001)», La Historia de la familia en la península ibérica (siglos XVI-XIX), Cuenca, Universidad de Castilla La Mancha.

PÉREZ GARCÍA, J.M. (2008): «Familias y hogares en Galicia y en la cornisa cantábrica durante el Antiguo Régimen», La Historia de la Familia en la Península Ibérica (siglos XVI-XIX), Cuenca, Universidad de Castilla La Mancha.

RUBIO PÉREZ, L. (2009):«Pobres y ricos. Estructura social, pobreza y asistencia en las comunidades campesinas en el Reino de León durante la Edad Moderna», Pobreza, marginación y asistencia en la Península Ibérica (siglos XVI-XIX), León, Universidad de León.

SPIKE, T., HARRINGTON, L., \& HARRINGTON M. (2007): «Si todo el mundo fuera Inglaterra: la teoría de Peter Laslett sobre la composición de los grupos domésticos vs. la realidad tapatía, 1821-1822», Estudios Sociales Nueva Época, 2, Guadalajara, Universidad de Guadalajara. 